\title{
Synthesis and properties of dental zirconia-leucite composites
}

\author{
MING KANG ${ }^{1,2}$, XIAOMING LIAO $^{1}$, GUANGFU YIN $^{1 *}$, XUN SUN $^{3}$, XING YIN $^{4}$, LU XIE $^{4}$ \\ and JUN LIU ${ }^{2}$ \\ ${ }^{1}$ College of Materials Science and Engineering, Sichuan University, Chengdu 610064, China \\ ${ }^{2}$ College of Material Science and Engineering, Southwest University of Science and Technology, Mianyang \\ 621010, China \\ ${ }^{3}$ Department of Urology, People's Hospital of Jinghong, Jinghong 666100, China \\ ${ }^{4}$ West China College of Stomatology, Sichuan University, Chengdu 610041, China
}

MS received 11 May 2009; revised 11 July 2009

\begin{abstract}
The dental zirconia-leucite composites were synthesized by high temperature solid-state method using potash feldspar, potassium carbonate and zirconia as raw materials. The mechanical properties and the coefficient of thermal expansion (CTE) of the prepared zirconia-leucite composites were tested. The results show that the bending strength, the fracture toughness and the metal-ceramic bonding strength of the prepared samples are about $110 \mathrm{MPa}, 3 \cdot 5 \mathrm{MPa} / \mathrm{m}^{1 / 2}$ and $45 \mathrm{MPa}$, respectively. The $\mathrm{CTE}$ was about $13 \cdot 73 \times 10^{-6}{ }^{\circ} \mathrm{C}^{-1}$ and close to that of $\mathrm{Ni}-\mathrm{Cr}$ dental alloy $\left(14.0 \times 10^{-6}{ }^{\circ} \mathrm{C}^{-1}\right)$. The results indicate that the introduction of zirconia is beneficial to the improvement in the mechanical properties and CTE adjustment of porcelain material. The clinical application of the zirconia-leucite composites with good metal-ceramic bonding strength in the dental restoration could be envisioned.
\end{abstract}

Keywords. Zirconia; leucite; metal-ceramic bond; mechanical properties.

\section{Introduction}

Dental defect is a common trauma of the oral cavity, which not only impairs people's health but also does harm to people's appearance. Porcelain-fused to metal (PFM) teeth has been widely used in clinical restoration due to their characteristics such as natural beauty, obdurability, wear resistance and corrosion resistance (Dent et al 1982; Hacher et al 1996; Kelly et al 1996; Könönen and Kivilahti 2001; Almilhatti et al 2003). Published results show that about half of PFM teeth crack or collapse in the clinical application, largely as a result of the poor performance of the porcelain powder (Liu et al 2008). For example, metal substrate and ceramic powders cannot match very well with each other in the linear coefficient of thermal expansion (CTE). In addition to that, the corresponding adhesive capability, bending strength and fracture toughness cannot meet the actual requirements. Generally, the chemical or mineral raw materials are usually selected to prepare the porcelain powders. Firstly the raw materials are mixed with the appropriate nucleating agent. Then leucite, which is widely adopted as the reinforcing material of dental ceramics in the clinical use (Mackert et al 1996; Yin et al 2003; Cesar et al 2005), is synthesized after three-step thermal processing of melting, nucleation and crystallization

\footnotetext{
*Author for correspondence (nic0700@scu.edu.cn)
}

(Mackert et al 2001). Leucite is usually added into the dental porcelain by the incongruent melting of potash feldspar or as a synthetic powder. The bulk of the porcelain is a glass matrix with a relatively small percentage of leucite crystal dispersed within it (Lee et al 2004). However, the preparation process is complicated and the synthetic conditions are difficult to control, which is unfavourable for this method. Research shows that many feldspar mineral materials such as feldspar, kaolinite, nepheline, zeolite and so on, which are similar to leucite in the component, can be transformed into leucite under high temperature (Hashimoto et al 2005). As is known, zirconia not only has superior mechanical properties and comparatively low CTE (about $9 \cdot 0 \times 10^{-6}{ }^{\circ} \mathrm{C}^{-1}$ ) in comparison with that of leucite (about $30 \times$ $\left.10^{-6}{ }^{\circ} \mathrm{C}^{-1}\right)$, but also has good biocompatibility, chemical stability, non-sensitive, good aesthetics and so on. Except for that, it could go with gums and mucous membrane well to achieve the good effects (Brecker 1956; Weiscin and Weistein 1962; Sollazzo et al 2008). Hence, zirconia was introduced in the synthesis system to improve the mechanical properties and adjust $\mathrm{CTE}$ of the as-prepared ceramics to match the CTE of $\mathrm{Ni}-\mathrm{Cr}$ alloy base (about $14.0 \times 10^{-6}{ }^{\circ} \mathrm{C}^{-1}$ ). Ni-Cr alloys, which have still been widely used as the substrate for the restoration of teeth in some developing countries because of the economical and other reasons, were adopted in our study.

In this paper, zirconia-leucite composites were synthesized through high-temperature solid-state reaction using 
potash feldspar, potassium carbonate and zirconia as raw materials. The mechanical properties of the obtained samples were examined on the electronic universal testing machine. The morphology, phase constituents, components and CTE were also characterized by scanning electron microscopy (SEM), X-ray diffraction (XRD), Raman spectroscopy, energy dispersive X-ray spectrometer (EDX) and thermal expansion instrument, respectively. The zirconia-leucite composites with good metal-ceramic bonding strength will have great potential in the clinical application of the dental porcelain restoration.

\section{Experimental}

\subsection{Synthesis of zirconia-leucite composites}

Zirconia-leucite composites were prepared through hightemperature solid-state reaction using potash feldspar (Qingyuan, China), analytical reagent potassium carbonate $\left(\mathrm{K}_{2} \mathrm{CO}_{3}\right)$ and $\mathrm{Y}_{2} \mathrm{O}_{3}$-stabilized zirconia $\left(\mathrm{ZrO}_{2}\right.$, Jiankun Chemical Co., China) as the main raw materials. The potash feldspar is mainly composed of $67 \cdot 62 \% \mathrm{SiO}_{2}, 18 \cdot 29 \% \mathrm{Al}_{2} \mathrm{O}_{3}$ and $9 \cdot 72 \% \mathrm{~K}_{2} \mathrm{O}$ (wt $\%$ ). As is known, $23 \% \mathrm{~K}_{2} \mathrm{O}$ in leucite is much higher than that in potash feldspar. Hence, in order to adjust the ratio of potassium oxide and high-temperature melting performance, potassium carbonate was introduced in our experiment. In this paper, $22 \cdot 39 \% \mathrm{~K}_{2} \mathrm{O}$ and $8 \% \mathrm{ZrO}_{2}$ was employed. Briefly, a certain amount of potash feldspar, potassium carbonate and zirconia were first placed in a nylon tank with 95 alumina CERAMIC BALLS as the milling media and ethanol as the solvent. Then the mixed materials were put into QM-1SP planetary-type ball mill to obtain uniform mixture. After drying, the mixture was then transferred into corundum crucible and sintered at $1200{ }^{\circ} \mathrm{C}$ for $1 \mathrm{~h}$ followed by natural cooling to room temperature. Finally, the sintered products were ground, milled and screened to obtain zirconia-leucite composite ceramic powders.

\subsection{Characterization of zirconia-leucite composites}

The bars with a dimension of $30 \times 5 \times 5 \mathrm{~mm}$ were prepared by uniaxial pressing of the zirconia-leucite composite ceramic powders at a pressure of $20 \mathrm{MPa}$ for $2 \mathrm{~min}$ and the compacts were sintered at $950{ }^{\circ} \mathrm{C}$ for $0.5 \mathrm{~h}$ followed by slow furnace cooling. The phase constituents and morphology of the asprepared samples were investigated by X-ray diffraction (XRD, D/max-III B-type, Japan) and Raman (Renishaw, InVia, England), scanning electron microscopy (SEM, Hitachi TM-1000, Japan), respectively. In order to reveal the microstructure of the materials, the sample for SEM characterization was etched with 5\% HF solution for $1 \mathrm{~min}$ and then cleaned with ultrasonic cleaning system for $10 \mathrm{~min}$ and dried for $24 \mathrm{~h}$ at room temperature. The CTE was measured by a Dilatometer (DIL402PC, Netzsch, Germany). The bending strength, fracture toughness and metal-ceramic bonding strength for the investigated samples were measured by an electronic universal testing machine (AG-IC $20 \mathrm{KN}$, Shimadzu, Japan). The elemental distribution of the metal-ceramic interface was analysed by the attached EDX of Hitachi-S4800 SEM. The bending strength, fracture toughness and metal-ceramic bonding strength were measured based on three-point bending test. But for the fracture toughness test, the method of single-edge notch beam (SENB) was adopted. The bars, which were prepared by uniaxial pressing of the prepared porcelain powders at a pressure of $20 \mathrm{MPa}$ for $2 \mathrm{~min}$, were first cut into a blade-thin slit with a size of $0.2 \times 2 \mathrm{~mm}$, and the compacts were sintered at $950{ }^{\circ} \mathrm{C}$ for $0.5 \mathrm{~h}$ followed by slow furnace cooling. Although the nominal dimension of the samples was $30 \times 5 \times 5 \mathrm{~mm}$, there were small variations in the real dimensions. Hence, width $b$ and thickness $h$ were measured and the bending strength $\delta_{b}$ can be calculated using (1). Fracture toughness, $K_{\mathrm{IC}}$, can be obtained according to (2) and (3)

$$
\begin{aligned}
\sigma_{b}= & 3 P L /\left(2 b h^{2}\right), \\
K_{\mathrm{IC}} & =Y\left\{3 P L /\left(2 b w^{2}\right)\right\} a^{1 / 2}, \\
Y= & 1.93-3.07(a / w)+14.53(a / w)^{2}-25 \cdot 07(a / w)^{3} \\
& +258.0(a / w)^{4},
\end{aligned}
$$

where $P$ is the load at the time of fracture; $L, w$ and $a$ are span, thickness and depth of the incision of the investigated sample, respectively.

Metal-ceramic bonding strength was determined by the method used in the international standard ISO9693:1999. The Ni-Cr alloy was supplied by Sichuan University, whose CTE was about $14.0 \times 10^{-6}{ }^{\circ} \mathrm{C}^{-1}$ and elastic modulus, $210 \mathrm{GPa}$. Briefly, Ni-Cr alloy was machined to a sheet with a size of $25 \times 5 \times 0.5 \mathrm{~mm}$ followed by grinding, polishing, sand blasting, removal of air and clearance treatment to remove surface contaminants. The size of the samples for bonding strength test was in accordance with the size prescribed in ISO9693:1999. In order to evaluate the bonding strength, a certain amount of regulators was mixed into the powders and then coated evenly on the $\mathrm{Ni}-\mathrm{Cr}$ alloy substrates with a brush. After drying and sintering at $960{ }^{\circ} \mathrm{C}$ for $0.5 \mathrm{~h}$, all the testing samples were well prepared. The samples were placed on two fulcrums with the ceramic side downward. The fracture force $F$ was obtained by the measurement of vertical force exerted in the mid point of the sample when the ceramic layer just broke. The value of the coefficient $k$ as a function of metal substrate thickness, $d_{\mathrm{M}}$ and metal elastic modulus, $E_{\mathrm{M}}$, was determined according to the international standard ISO9693:1999. The bonding strength, $\tau_{\mathrm{b}}$, was calculated according to the formula $\tau_{\mathrm{b}}=k \times F$. All the experiments were carried out in quintuplicate. The results were presented as mean \pm standard 
deviation. Significant differences were determined by $t$-test. $P<0 \cdot 05$ was considered to be significant.

\section{Results and discussion}

\subsection{Mechanical properties}

The bending strength, fracture toughness and the metalceramic bonding strength of samples are 109.93 $\pm 7.01 \mathrm{MPa}$, $3 \cdot 47 \pm 0 \cdot 32 \mathrm{MPa} / \mathrm{m}^{1 / 2}$ and $45 \cdot 09 \pm 0 \cdot 11 \mathrm{MPa}$, respectively, significantly higher than the corresponding value of $50 \mathrm{MPa}$, $2.5 \mathrm{MPa} / \mathrm{m}^{1 / 2}$ and $25 \mathrm{MPa}$ prescribed in ISO9693:1999 $(p<$ $0 \cdot 05)$. The results indicate that the zirconia-leucite composites exhibit good mechanical properties.

\subsection{SEM analysis}

Figure 1 is the SEM photograph of hydrofluoric acid etched zirconia-leucite composites. From figure 1, it can be seen that a large number of tetragonal phase leucite crystals exists. A small amount of zirconia crystal with a size of about $0 \cdot 5-2 \mu \mathrm{m}$ scattered between the leucite crystals can also be observed.

According to the theory of Griffith, micro-cracks, when leucite grains evenly distribute in the glass phase, there are a lot of small cracks and defects in ceramic materials. Under the external stress, cracks begin to expand across the grain boundary or along the direction paralleling to the grain boundary, thus there is a big increase in the number of crack expansion paths, also in the resistance to crack expansion and helpful to improve the mechanical strength of ceramic materials.

\subsection{XRD and Raman analysis}

The XRD pattern and Raman spectroscopy of the composite powders are shown in figures 2 and 3, respectively. From

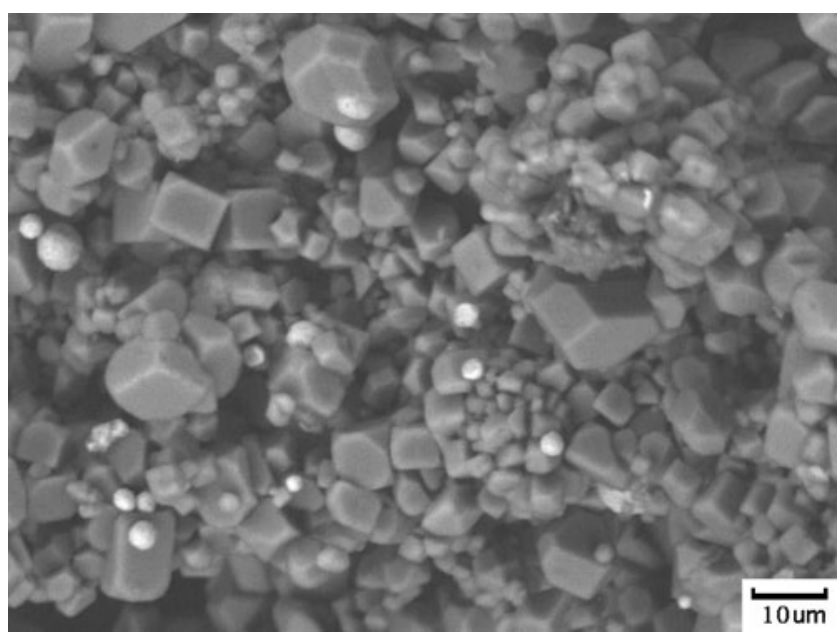

Figure 1. SEM photograph of hydrofluoric acid etched zirconialeucite composites.

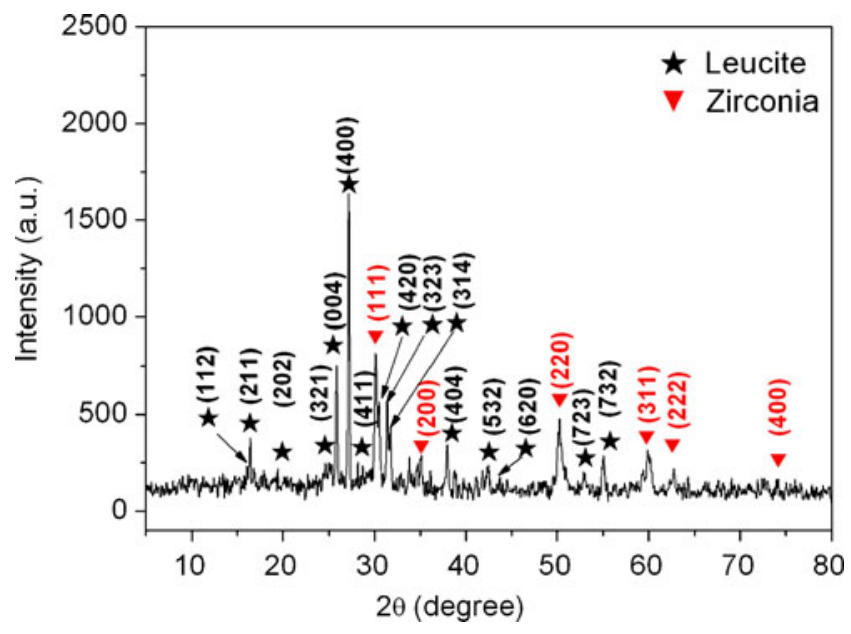

Figure 2. XRD pattern of zirconia-leucite composites.

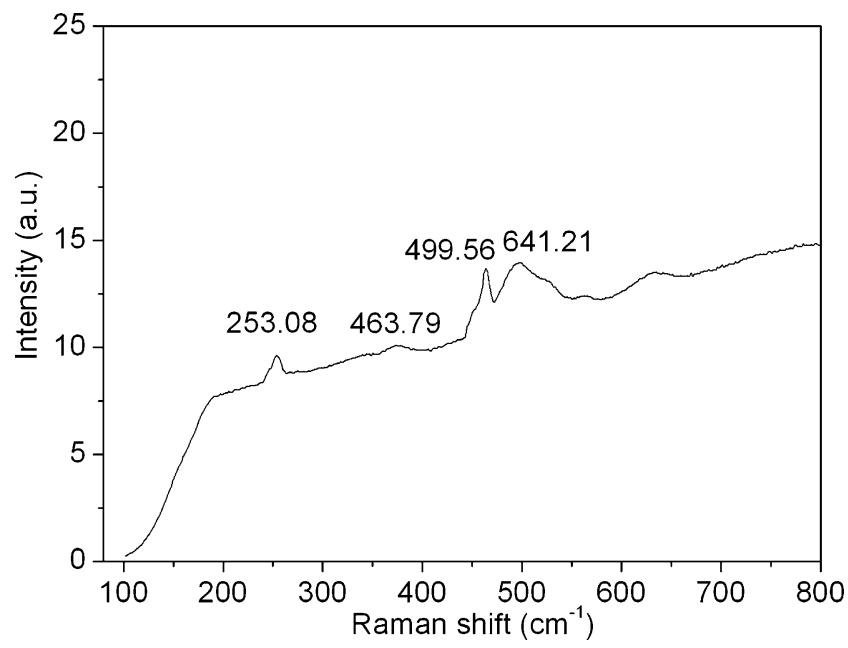

Figure 3. Raman spectra of zirconia-leucite composites.

figure 2 , it can be seen that only diffraction peaks of zirconia (No. 49-1672) and leucite (No. 38-1423) are detected, indicating that the main crystal phases of the sample are zirconia and leucite crystal.

From figure 3, the characteristic peak of leucite crystal at $499.56 \mathrm{~cm}^{-1}$ in terms of the literature through the standard card (Renishaw ro2-S/NH 14030) can be observed. In addition, the tetragonal zirconia characteristic absorption peaks around 253.18, 463.79 and $642 \mathrm{~cm}^{-1}$ are detected (Grover et al 2007). Hence, it could be safely concluded that there is zirconia in the samples and the crystalline phase remained unchangeable, which is in line with the XRD analysis. In short, during the preparation of ceramic powders, zirconia crystal phase does not make any transformation, which is helpful to the increase of the fracture toughness. The reason is that the formation of the solid solution between some oxides (such as $\mathrm{CaO}$ and $\mathrm{Al}_{2} \mathrm{O}_{3}$ ) in the raw materials and $\mathrm{ZrO}_{2}$ leads to the change of the internal structure of the zirconia crystal, which results in the 
increase of the chemical energy barrier of the transformation from tetragonal zirconia $(t)$ to the monoclinic zirconia $(m)$ and improves the stability of the $t$-phase, also subsequently decline the initial phase change temperature. Hence, metastable $t-\mathrm{ZrO}_{2}$ can be retained at room temperature. When the external force is employed on the ceramic materials,

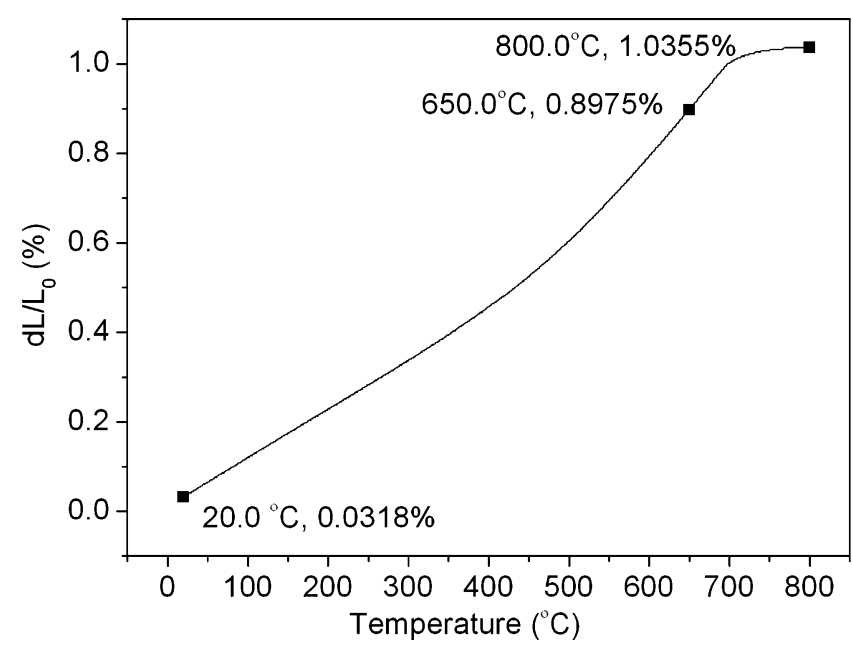

Figure 4. CTE curve of zirconia-leucite composites. martensitic phase transformation for metastable $t-\mathrm{ZrO}_{2}$ will happen and consequently increase their toughness. As a result, the introduction of zirconia increased the fracture toughness to about $3.5 \mathrm{MPa} / \mathrm{m}^{1 / 2}$, a $40 \%$ increase compared with the prescribed value $\left(2 \cdot 5 \mathrm{MPa} / \mathrm{m}^{1 / 2}\right)$ in ISO9693:1999.

\subsection{CTE analysis}

CTE curve of the prepared zirconia-leucite composites is shown in figure 4 . From figure 4 , it can be seen that with the increasing temperature, the thermal expansion rate gradually increases and reaches to $0.031 \%, 0.8975 \%$ and $1.0355 \%$ at $20{ }^{\circ} \mathrm{C}, 650{ }^{\circ} \mathrm{C}$ and $800{ }^{\circ} \mathrm{C}$, respectively. There is linear expansion during the range of $20-650{ }^{\circ} \mathrm{C}$. According to the formula, $\alpha=\Delta L / L_{0} \times \Delta T \pm 5 \cdot 7 \times 10^{-7}$, the CTE of the samples is about $13 \cdot 75 \times 10^{-6}{ }^{\circ} \mathrm{C}^{-1}$ and was close to that of the nickel-chromium alloy (about $14 \cdot 0 \times 10^{-6}{ }^{\circ} \mathrm{C}^{-1}$ ). This shows that the addition of zirconia is beneficial to the adjustment of CTE of ceramic materials and ensures the matching of the ceramic materials with nickel-chromium alloy substrate in the thermal expansion performance. From figure 4, it can also be observed that the CTE curve tends to be parallel above $800{ }^{\circ} \mathrm{C}$, indicating that the CTE of ceramic materials remained unchangeable at higher temperature.
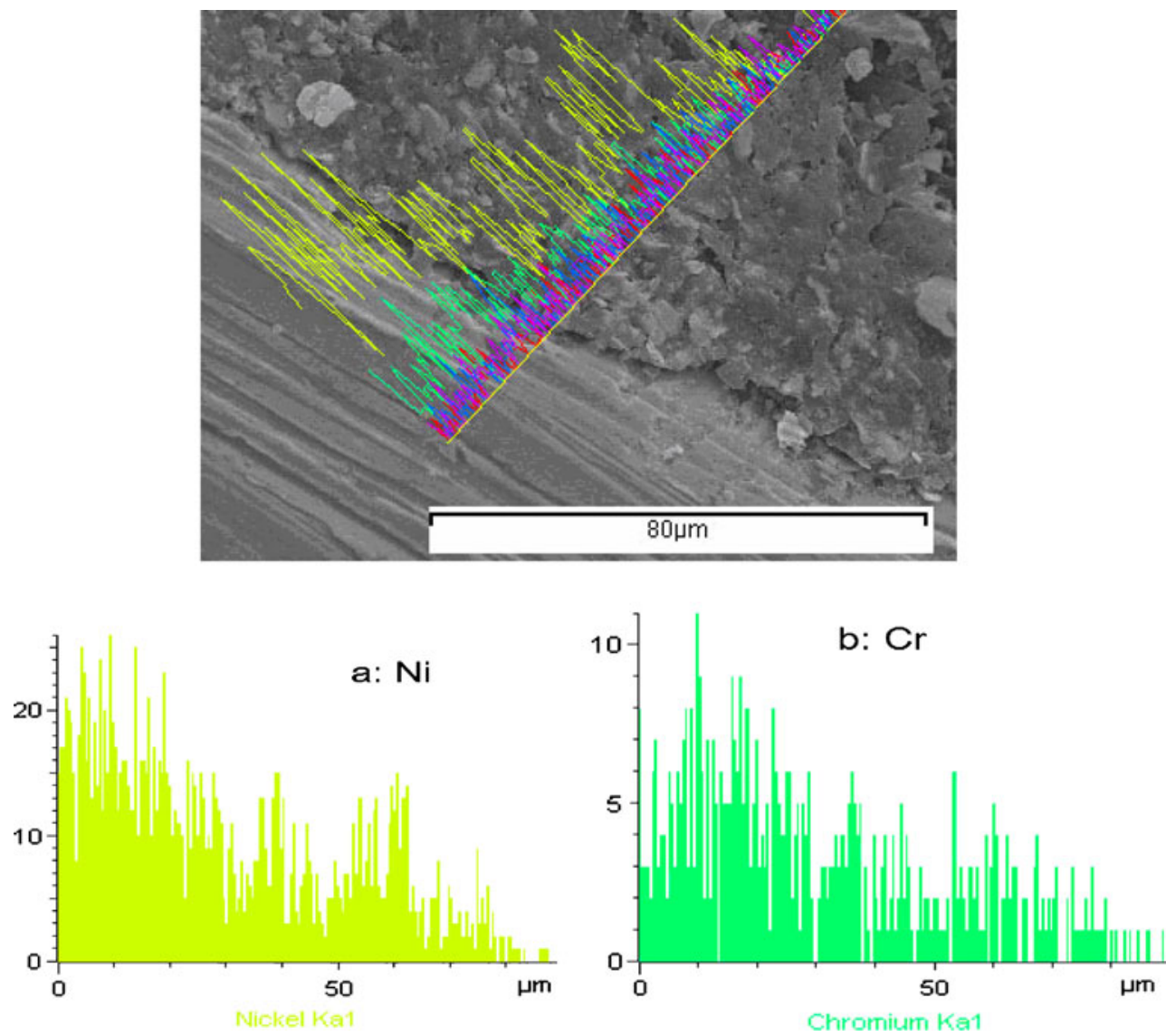

Figure 5. EDX spectra of the interface between $\mathrm{Ni}-\mathrm{Cr}$ alloy and ceramic. 


\subsection{Metal-ceramic interface analysis}

SEM was employed to examine the metal-ceramic interface and EDX test was used to investigate the elemental distribution along the direction from the metal layer to the ceramic layer (shown in figure 5). From figure 5, no obvious stratification between the metal and ceramic can be observed. In the EDX spectra, yellow, green, red, purple and blue curves were corresponding to content change of $\mathrm{Ni}$, $\mathrm{Cr}, \mathrm{K}, \mathrm{Si}$ and $\mathrm{Al}$ elements, respectively, showing that the interdiffusion of atoms occurred during sintering. Among them, the distribution of the $\mathrm{Ni}$ and $\mathrm{Cr}$ elements was shown in figures $5 \mathrm{a}$ and $\mathrm{b}$, respectively. It can be seen that the content of $\mathrm{Ni}$ and $\mathrm{Cr}$ elements decreases along the direction from the metal layer to the ceramic layer, indicating that $\mathrm{Ni}$ and $\mathrm{Cr}$ diffuse into the ceramic layer, especially the diffusion of element $\mathrm{Ni}$ is more remarkable. As is known to all, the reaction of metal-porcelain interfaces is complicated. In these complex systems, diffusion bond is established not only by mutual interdiffusion but also by simultaneous solid-state reactions (Hegedüs et al 2002; Liu et al 2008). The formation of compound interface, which mainly resulted from the dissolution and diffusion of the metal and ceramic powders with each other, is very favourable to the increase of metal-ceramic bonding strength. From the relationship between Gibbs free energy and temperature for the metal oxide (Steiner et al 1997), the Gibbs free energy of generating $\mathrm{Cr}_{2} \mathrm{O}_{3}$ is lower than that of $\mathrm{Al}_{2} \mathrm{O}_{3}$ at $1233 \cdot 15 \mathrm{~K}\left(960{ }^{\circ} \mathrm{C}\right)$. That is to say, $\mathrm{Cr}$ has greater affinity with $\mathrm{O}$ than $\mathrm{Al}$. Hence, $\mathrm{Cr}$ of $\mathrm{Ni}-\mathrm{Cr}$ alloy can be dissolved and spread out to the porcelain interface when the ceramic powder was in a molten state. Meanwhile, it could substitute $\mathrm{Al}$ of $\mathrm{Al}_{2} \mathrm{O}_{3}$ in porcelain powder and consequently prompt the formation of $\mathrm{Cr}_{2} \mathrm{O}_{3}$. It has also been reported that a very thin $\mathrm{Cr}_{2} \mathrm{O}_{3}$ layer already exists on the surface of the $\mathrm{Ni}-\mathrm{Cr}$ alloy at the start of the sintering process (Hegedüs et al 2002). On the other hand, the replaced $\mathrm{Al}$ and $\mathrm{Ni}$ may react and then $\mathrm{A}_{1} \mathrm{Ni}_{3}$ is produced (Mackert et al 1996). These suggest that the interface is an integration of diffusion type and compound type, which acts as the transition layer between the $\mathrm{Ni}-\mathrm{Cr}$ alloy layer and porcelain layer, thereby reducing interface defects and improving the adhesion strength of metal-ceramic interface. At the same time, the different layers of oxides also contribute to surface wetting effects of the molten porcelain on the surface of metal and consequently enhance the metal-ceramic bonding strength.

\section{Conclusions}

The dental zirconia-leucite composites were synthesized by high temperature solid-state method using potash feldspar, potassium carbonate and zirconium oxide as raw materials. The bending strength, the fracture toughness and the metalceramic bonding strength of the investigated sample are about $110 \mathrm{MPa}, 3 \cdot 5 \mathrm{MPa} / \mathrm{m}^{1 / 2}$ and $45 \mathrm{MPa}$, respectively. The CTE was about $13.73 \times 10^{-6}{ }^{\circ} \mathrm{C}^{-1}$ and close to that of $\mathrm{Ni}-\mathrm{Cr}$ dental alloy $\left(14 \cdot 0 \times 10^{-6}{ }^{\circ} \mathrm{C}^{-1}\right)$. The introduction of zirconia is beneficial to the improvement in the mechanical properties of the porcelain materials, and the matching of the CTE between the metal substrates and porcelain powders. The zirconia-leucite composites with good metal-ceramic bonding strength will have great potential in the clinical application of dental restoration.

\section{Acknowledgements}

This work was financially supported by the National Natural Science Foundation of China (10476024) and Science and Technology Bureau of Sichuan province (2006 J13-059). The support of the restoration centre for dental prosthetics, West China College of Stomatology of Sichuan University is also gratefully acknowledged.

\section{References}

Almilhatti H J, Giampaolo E T, Vergani C E, Machado A L and Pavarina A C 2003 J. Dent. 31205

Brecker C S 1956 J. Prosthet. Dent. 6801

Cesar P F, Yoshimura H N, Junior W G M and Okada C Y 2005 J. Dent. 33721

Dent R J, Preston J D, Moffa J P and Caputo A 1982 J. Prosthet. Dent. 4759

Grover V, Shukla R and Tyagi A K 2007 Scr. Mater. 57699

Hacher C H, Wagner W C and Razoog M E 1996 J. Prosthet. Dent. 7514

Hashimoto S, Sato F, Honda S, Hideo A and Fukuda K 2005 J. Ceram. Soc. Jpn 113488

Hegedüs C, Daróczi L, Kökényesi V and Beke D L 2002 J. Dent. Res. 81334

Kelly J R, Nishimura I and Campbell S D 1996 J. Prosthet. Dent. 7518

Könönen M and Kivilahti J 2001 J. Dent. Res. 80848

Lee Y K, Park H Y, Shim J E, Kim K N and Lee K W 2004 J. Non-cryst. Solids 349200

Liu J, Qiu X M, Zhu S and Sun D Q 2008 Mater. Sci. Eng. A497 421

Mackert J R, Khajotia S S, Russell C M and Williams A L 1996 Dent. Mater. 128

Mackert J R, Twiggs S W, Russell C M and Williams A L 2001 J. Dent. Res. 801574

Sollazzo V, Pezzetti F, Scarano A, Piattelli A, Bignozzi C A, Massari L, Brunelli G and Carinci F 2008 Dent. Mater. 24357

Steiner P J, Kelly R J and Giuseppetti A A 1997 Int. J. Prosthodont. 10375

Weiscin M and Weistein A B 1962 US Patent 3052983

Yin L, Jahanmir S and Ives L K 2003 Wear 255975 